\title{
Trends in Incidence of Cancers of the Oral Cavity and Pharynx - United States 2007-2016
}

\begin{abstract}
Taylor D. Ellington, $\mathrm{MPH}^{1}$; S. Jane Henley, $\mathrm{MSPH}^{1}$; Virginia Senkomago, $\mathrm{PhD}^{1}$; Mary Elizabeth O’Neil, $\mathrm{MPH}^{1}$; Reda J. Wilson, MPH ${ }^{1}$;
\end{abstract} Simple Singh, $\mathrm{MD}^{1}$; Cheryll C. Thomas, $\mathrm{MSPH}^{1}$; Manxia Wu, MD ${ }^{1}$; Lisa C. Richardson, $\mathrm{MD}^{1}$

Cancers of the oral cavity and pharynx account for 3\% of cancers diagnosed in the United States* each year. Cancers at these sites can differ anatomically and histologically and might have different causal factors, such as tobacco use, alcohol use, and infection with human papillomavirus (HPV) (1). Incidence of combined oral cavity and pharyngeal cancers declined during the 1980s but began to increase around 1999 $(2,3)$. Because tobacco use has declined in the United States, accompanied by a decrease in incidence of many tobaccorelated cancers, researchers have suggested that the increase in oral cavity and pharynx cancers might be attributed to anatomic sites with specific cell types in which HPV DNA is often found $(4,5)$. U.S. Cancer Statistics ${ }^{\dagger}$ data were analyzed to examine trends in incidence of cancers of the oral cavity and pharynx by anatomic site, sex, race/ethnicity, and age group. During 2007-2016, incidence rates increased for cancers of the oral cavity and pharynx combined, base of tongue, anterior tongue, gum, tonsil, oropharynx, and other oral cavity and pharynx. Incidence rates declined for cancers of the lip, floor of mouth, soft palate and uvula, hard palate, hypopharynx, and nasopharynx, and were stable for cancers of the cheek and other mouth and salivary gland. Ongoing implementation of proven population-based strategies to prevent tobacco use initiation, promote smoking cessation, reduce excessive alcohol use, and increase HPV vaccination rates might help prevent cancers of the oral cavity and pharynx.

Data on new cases of cancers of the oral cavity and pharynx (International Classification of Diseases for Oncology, Third Edition: C00-C14) ${ }^{\S}$ reported during 2007-2016, the most

\footnotetext{
*https://www.cdc.gov/cancer/dataviz.

$\dagger^{\dagger}$ https://www.cdc.gov/uscs.

$\$$ http://www.iacr.com.fr/index.php?option = com_content\&view = category\&layout $=$ blog\&id $=100 \&$ Itemid $=577$.
}

recently available data, were obtained from U.S. Cancer Statistics. U.S. Cancer Statistics includes population-based cancer registry data from CDC's National Program of Cancer

\section{INSIDE}

439 Progress Toward Measles Elimination - Eastern Mediterranean Region, 2013-2019

446 Community Transmission of SARS-CoV-2 at Two Family Gatherings — Chicago, Illinois, FebruaryMarch 2020

451 Timing of Community Mitigation and Changes in Reported COVID-19 and Community Mobility — Four U.S. Metropolitan Areas, February 26-April 1, 2020

458 Hospitalization Rates and Characteristics of Patients Hospitalized with Laboratory-Confirmed Coronavirus Disease 2019 - COVID-NET, 14 States, March 1-30, 2020

465 Geographic Differences in COVID-19 Cases, Deaths, and Incidence - United States, February 12 April 7, 2020

472 Transmission of COVID-19 to Health Care Personnel During Exposures to a Hospitalized Patient Solano County, California, February 2020

477 Characteristics of Health Care Personnel with COVID-19 - United States, February 12-April 9, 2020

482 Notes from the Field: Brucella abortus RB51 Infections Associated with Consumption of Raw Milk from Pennsylvania — 2017 and 2018

484 QuickStats

Continuing Education examination available at https://www.cdc.gov/mmwr/mmwr_continuingEducation.html

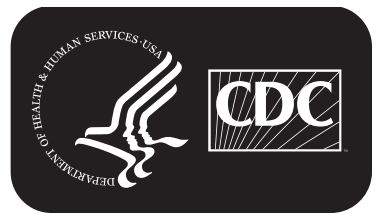

U.S. Department of Health and Human Services Centers for Disease Control and Prevention 
Registries and the National Cancer Institute's Surveillance, Epidemiology, and End Results (SEER) program. This report covers the entire U.S. population during the 10-year period. Only microscopically confirmed cases were included.

Annual incidence rates per 100,000 persons used modified annual population estimates in the denominator (as an approximation of person-years) and were age-adjusted by the direct method to the 2000 U.S. standard population using SEERStat software (version 8.3.6; National Cancer Institute). Trends in rates were estimated using joinpoint regression, with a maximum of one joinpoint allowed (JoinPoint version 4.6.0; National Cancer Institute). Average annual percentage change (AAPC) for 2007-2016 was calculated using the average of the slope coefficients of the underlying joinpoint regression lines with the weights equal to the length of each segment over the interval. To determine whether AAPCs were significantly different from zero, a t-test was used for 0 joinpoints, and a z-test was used for 1 joinpoint. Rates were considered to increase or decrease if $\mathrm{p}<0.05$. Rates were examined by anatomic site, sex, race/ethnicity (five mutually exclusive groups, including non-Hispanic white [white], non-Hispanic black [black], non-Hispanic American Indian/Alaska Native [AI/AN], nonHispanic Asian/Pacific Islanders [A/PI], and Hispanic) and age group (20-39, 40-49, 50-59, 60-69, 70-79, and $\geq 80$ years). Rates also were examined by association with HPV, based on

$\overline{\text { Shttps://seer.cancer.gov/popdata. }}$ studies that examined the presence of HPV DNA in a sample of cancer tissue specimens (G). HPV-associated cancers included squamous cell cancer types at the base of tongue, pharyngeal tonsils, anterior and posterior tonsillar pillars, glossotonsillar sulci, soft palate and uvula, and lateral and posterior pharyngeal walls. All other cancers were considered not HPV-associated.

During 2007-2016, incidence rates increased for cancers of the oral cavity and pharynx combined $(0.6 \%$ per year on average), other oral cavity and pharynx (3.4\%), base of tongue (1.8\%), anterior tongue (1.8\%), gum (1.9\%), tonsil (2.4\%), and oropharynx (1.9\%) (Figure). Rates declined for cancers of the soft palate and uvula $(-3.7 \%)$, hard palate $(-0.9 \%)$, floor of mouth $(-3.1 \%)$, lip $(-2.7 \%)$, hypopharynx $(-2.4 \%)$, and nasopharynx $(-1.3 \%)$; and were stable for cancers of the cheek and other mouth and salivary gland. When cancers of the oral cavity and pharynx were grouped by association with HPV, HPV-associated cancers increased $2.1 \%$ per year on average, whereas cancers not associated with HPV decreased $0.4 \%$ per year on average.

Several anatomic sites are commonly grouped in the category "oral cavity and pharynx" (Table 1). Rates for all cancers of the oral cavity and pharynx combined increased among whites and A/PI, decreased among blacks and Hispanics, and were stable among AI/AN (Table 2). When the anatomic sites with increasing incidence trends were examined by race/ethnicity, rates increased only among whites with three exceptions: rates of cancers of the tonsil increased among AI/AN and of the anterior tongue and gum among A/PI. Rates of cancers

The MMWR series of publications is published by the Center for Surveillance, Epidemiology, and Laboratory Services, Centers for Disease Control and Prevention (CDC), U.S. Department of Health and Human Services, Atlanta, GA 30329-4027.

Suggested citation: [Author names; first three, then et al., if more than six.] [Report title]. MMWR Morb Mortal Wkly Rep 2020;69:[inclusive page numbers].

\section{Centers for Disease Control and Prevention}

Robert R. Redfield, MD, Director

Anne Schuchat, MD, Principal Deputy Director

Chesley L. Richards, MD, MPH, Deputy Director for Public Health Science and Surveillance

Rebecca Bunnell, PhD, MEd, Director, Office of Science

Arlene Greenspan, PhD, Acting Director, Office of Science Quality, Office of Science

Michael F. Iademarco, MD, MPH, Director, Center for Surveillance, Epidemiology, and Laboratory Services

MMWR Editorial and Production Staff (Weekly)

Charlotte K. Kent, PhD, MPH, Editor in Chief Jacqueline Gindler, MD, Editor

Paul Z. Siegel, MD, MPH, Guest Associate Editor

Mary Dott, MD, MPH, Online Editor

Terisa F. Rutledge, Managing Editor

Douglas W. Weatherwax, Lead Technical Writer-Editor

Glenn Damon, Soumya Dunworth, PhD, Teresa M. Hood, MS, Technical Writer-Editors

Michelle E. Bonds, MBA

Matthew L. Boulton, MD, MPH

Carolyn Brooks, ScD, MA

Jay C. Butler, MD

Virginia A. Caine, MD
Martha F. Boyd, Lead Visual Information Specialist Maureen A. Leahy, Julia C. Martinroe, Stephen R. Spriggs, Tong Yang, Visual Information Specialists

Quang M. Doan, MBA, Phyllis H. King,

Terraye M. Starr, Moua Yang,

Information Technology Specialists

MMWR Editorial Board

Timothy F. Jones, MD, Chairman

Katherine Lyon Daniel, PhD

Jonathan E. Fielding, MD, MPH, MBA

David W. Fleming, MD

William E. Halperin, MD, DrPH, MPH

Jewel Mullen, MD, MPH, MPA

Jeff Niederdeppe, PhD

\author{
Patricia Quinlisk, MD, MPH \\ Patrick L. Remington, MD, MPH \\ Carlos Roig, MS, MA \\ William Schaffner, MD \\ Morgan Bobb Swanson, BS
}


FIGURE. Trends in incidence of cancers of the oral cavity and pharynx, ${ }^{*},+\S$ by cancer anatomic site, United States, $2007-2016$

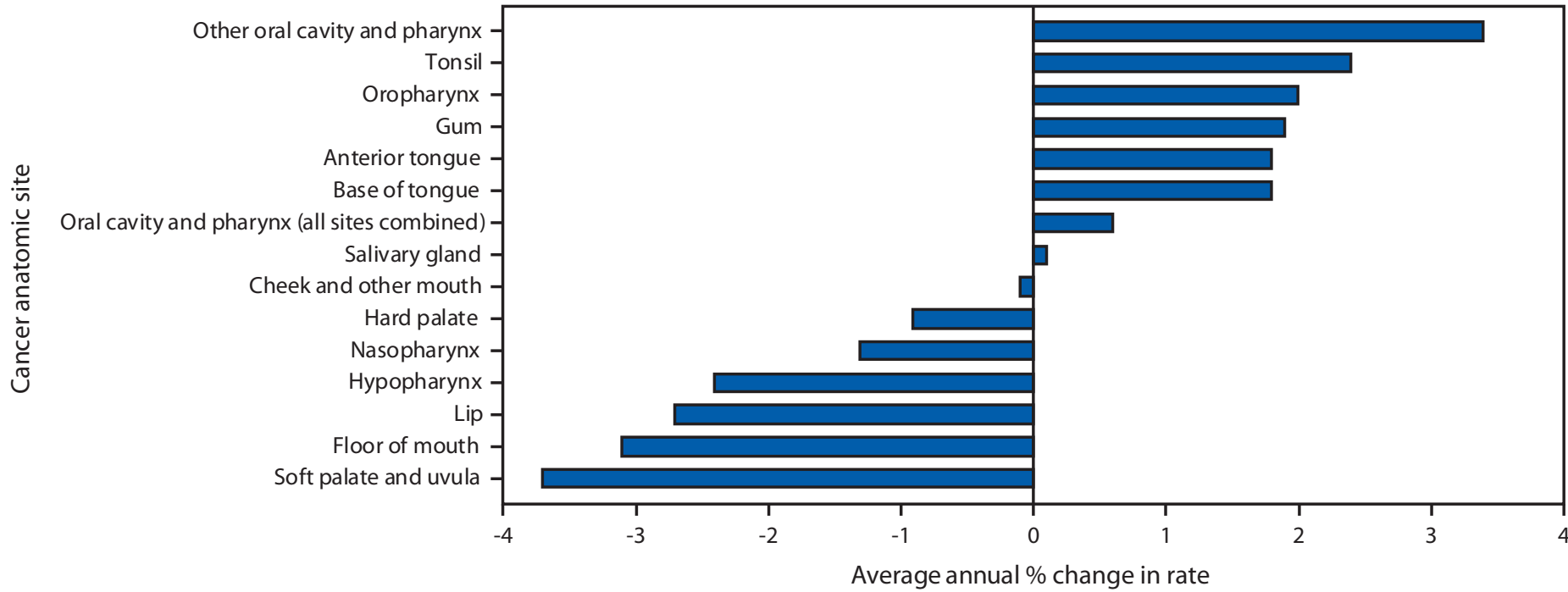

\footnotetext{
* Cancer incidence data were compiled from cancer registries that meet the data quality criteria for all invasive cancer sites combined, representing $100 \%$ of the U.S. population.

† Annual percentage changes were statistically significant (at p<0.05) for all sites except "Salivary gland" and "Cheek and other mouth," which had rates considered stable.

$\S$ "Other oral cavity and pharynx" cancers included International Classification of Diseases for Oncology, Third Edition (ICD-O-3) codes C14.0 (Pharynx NOS), C14.2 (Waldeyers ring), and C14.8 (Overlapping lesion of lip, oral cavity, and pharynx).
}

TABLE 1. Cancers of oral cavity and pharynx with ICD-O-3 code by anatomic site and HPV association status,* — United States, 2007 and 2016

\begin{tabular}{|c|c|c|c|c|}
\hline \multirow[b]{2}{*}{ Anatomic site } & \multirow[b]{2}{*}{ ICD-O-3 code } & \multirow[b]{2}{*}{ HPV-associated } & \multicolumn{2}{|c|}{ No. of cases (\%) } \\
\hline & & & 2007 & 2016 \\
\hline Oral cavity and pharynx (all sites) & $\mathrm{C} 00-\mathrm{C} 14$ & No & $35,076(100)$ & $44,419(100)$ \\
\hline Lip & C00.0-C00.9 & No & $2,048(6)$ & $1,847(4)$ \\
\hline Base of tongue & C01.9, C02.4, C02.8 & Yes & $5,661(16)$ & $8,164(18)$ \\
\hline Anterior tongue & C02.0-C02.3, C02.9 & No & 4,422 (13) & $6,155(14)$ \\
\hline Floor of mouth & C04.0-C04.9 & No & $2,073(6)$ & $1,978(4)$ \\
\hline Gum & C03.0, C03.1, C03.9 & No & $1,215(3)$ & $1,727(4)$ \\
\hline Soft palate and uvula & C05.1, C05.2 & Yes & $870(2)$ & $743(2)$ \\
\hline Hard palate & C05.0, C05.8, C05.9 & No & $767(2)$ & $859(2)$ \\
\hline Cheek and other mouth & C06.0-C06.9 & No & $2,057(6)$ & $2,463(6)$ \\
\hline Salivary gland & C07.9-C08.9 & No & $3,862(11)$ & $4,433(10)$ \\
\hline Tonsil & C09.0-C09.9 & Yes & $5,791(17)$ & $8,792(20)$ \\
\hline Oropharynx & C10.0-C10.9 & Yes & $1,507(4)$ & $2,165(5)$ \\
\hline Nasopharynx & C11.0-C11.9 & No & $1,779(5)$ & $1,788(4)$ \\
\hline Hypopharynx & C12.9-C13.9 & No & $2,307(7)$ & $2,211(5)$ \\
\hline Other oral cavity and pharynx & C14.0-C14.8 & Yes & $717(2)$ & $1,094(2)$ \\
\hline
\end{tabular}

Abbreviations: HPV = human papilloma virus; ICD-O-3 = International Classification of Diseases for Oncology, Third Edition.

* HPV-associated cancers are defined as cancers at specific anatomic sites with specific cell types in which HPV DNA frequently is found. These include ICD-O-3 site codes C01.9, C02.4, C02.8, C05.1, C05.2, C09.0, C09.8, C09.9, C10.0, C10.1, C10.2, C10.3, C10.4, C10.8, C10.9, C14.0, C14.2, and C14.8, with squamous cell carcinomas (histology codes: 8050-8084 and 8120-8131).

of the base of the tongue, tonsil, and oropharynx decreased among blacks.

Rates for all cancers of the oral cavity and pharynx combined increased among males but were stable among females. Among females, rates increased for cancers of the anterior tongue, gum, and tonsil but decreased for cancers of the floor of mouth, soft palate and uvula, nasopharynx, and hypopharynx, and were stable for other sites. A similar pattern was observed among males except that rates also decreased for cancer of the lip, increased for cancers of the base of tongue, oropharynx, and other oral cavity and pharynx, and were stable only for hard palate, cheek and other mouth, and salivary gland.

By age group, rates for all cancers of the oral cavity and pharynx combined increased among persons aged $50-79$ years, decreased among those aged 40-49 years, and were stable among those aged $20-39$ and $\geq 80$ years. Among sites with 
increasing rate trends, the increases were mainly driven by increases among persons aged 50-79 years; those rates were generally stable or decreased among persons aged $20-49$ years and increased or were stable among those aged $\geq 80$ years. All other rates were stable or could not be calculated because of small number of cases.

\section{Discussion}

During 2007-2016, the incidence of cancers of the oral cavity and pharynx combined increased, despite decreases in several anatomic sites, including the nasopharynx, hypopharynx, lip, and floor of mouth. The overall increase appears to be driven by increases in cancers of the tonsil, base of tongue, oropharynx, and other cancers of the oral cavity and pharynx, which are HPV-associated, as well as by those of gum and anterior tongue.

Declines in tobacco use might have contributed to the decreases observed in some sites ( 7 ). Population-based tobacco control measures (including high-impact antitobacco mass media campaigns, tobacco price increases, and comprehensive smoke-free laws) are proven to prevent tobacco use initiation and promote smoking cessation, ${ }^{* *}$ but they are not implemented equally in all U.S. states and communities. ${ }^{\dagger \dagger}$ Similarly, state alcohol control policies and alcohol screening are effective in reducing excessive alcohol use but are underutilized (8). Tobacco and alcohol use are still common in the United States; in $2018,14 \%$ of the adult population reported current cigarette smoking, and $27 \%$ reported binge drinking. ${ }^{\$ \$}$ To reduce the risk for cancers of the oral cavity and pharynx, communities might benefit from broader application of evidence-based interventions and targeted efforts among groups with high prevalence of tobacco and alcohol use or high cancer rates. 99

The overall increasing trend in oral cancer rates was the result of a combination of increasing rates among whites and $\mathrm{A} / \mathrm{PI}$, stable rates in AI/AN, and decreasing rates among blacks and Hispanics. A previous study found rates of oropharyngeal squamous cell cancers increased the most among white men compared with other racial/ethnic groups (4). Differences in sexual behavior might account for the higher rate; compared with other racial/ethnic groups, white men report an earlier age at oral sex initiation and have a higher number of oral sex partners which have been shown to be risk factors for exposure to HPV infection (9).

\footnotetext{
** https://www.cdc.gov/tobacco/stateandcommunity/best_practices/index. htm? source $=$ govdelivery.

$\dagger^{\dagger}$ https://www.cdc.gov/statesystem/.

$\$ \$$ https://www.healthypeople.gov/2020/topics-objectives.

99 https://www.thecommunityguide.org/topic/excessive-alcohol-consumption; https://www.thecommunityguide.org/topic/tobacco.
}

\section{Summary}

What is already known about this topic?

Oral cavity and pharynx cancers account for $3 \%$ of cancers diagnosed annually in the United States; risk factors include tobacco use, excessive alcohol consumption, and human papilloma virus (HPV) infection.

What is added by this report?

During 2007-2016, incidence of cancers of the oral cavity and pharynx combined increased, despite decreases in those at multiple anatomic sites. The overall increase was driven by increases in HPV-associated cancers of the tonsil, base of tongue, oropharynx, other oral cavity and pharynx, and the gum and anterior tongue.

What are the implications for public health practice?

Broader application of proven strategies to prevent tobacco use initiation, promote smoking cessation, reduce excessive alcohol consumption, and increase HPV vaccination rates can help reduce the incidence of these cancers.

Public health efforts that focus on increasing HPV vaccination $^{* * *}$ are an essential component of cancer prevention. Routine HPV vaccination is recommended for all persons at age 11 or 12 years, with catch-up vaccination through age 26 years. ${ }^{\dagger \dagger}$ CDC's National Comprehensive Cancer Control Program supports cancer prevention efforts in all 50 states, the District of Columbia, tribal organizations, and U.S. territories; and, in collaboration with CDC's National Center for Immunization and Respiratory Diseases (NCIRD), supports activities to promote and provide access to HPV vaccine. CDC's Division of Cancer Prevention and NCIRD currently fund the American Cancer Society to convene partners at the National HPV Vaccination Roundtable to support activities that increase HPV vaccination coverage. ${ }^{\$ \$ \$}$ There are no data on efficacy of vaccination on oral cavity and pharyngeal cancers from clinical trials, but these cancers are caused by HPV types that are targeted by available vaccines (10).

The findings in this report are subject to at least three limitations. First, delays in cancer reporting might result in an underestimate of incidence. Second, cancer registries do not routinely collect or report information about risk factors such as HPV infection, tobacco use, or alcohol use, so it was not possible to determine whether cancers occurred in persons exposed to these risk factors. Finally, because of the complexity of this anatomic region and potential difficulty in determining precisely where cancer originated, the anatomic site for some cases might have been incorrectly classified.

\footnotetext{
*** https://www.cdc.gov/vaccines/vpd/hpv/hcp/recommendations.html.

${ }^{\dagger \dagger \dagger}$ https://www.cdc.gov/cancer/ncccp/index.htm; https://www.cdc.gov/hpv/ partners/index.html; https://www.thecommunityguide.org/topic/ vaccination.

$\$ \$ \$$ https://hpvroundtable.org/
} 
TABLE 2. Annual rate*,+ and average annual percentage change (AAPC) in rates of cancers of the oral cavity and pharynx, by trends, anatomic site, sex, race/ethnicity, and age group at diagnosis - United States, 2007-2016

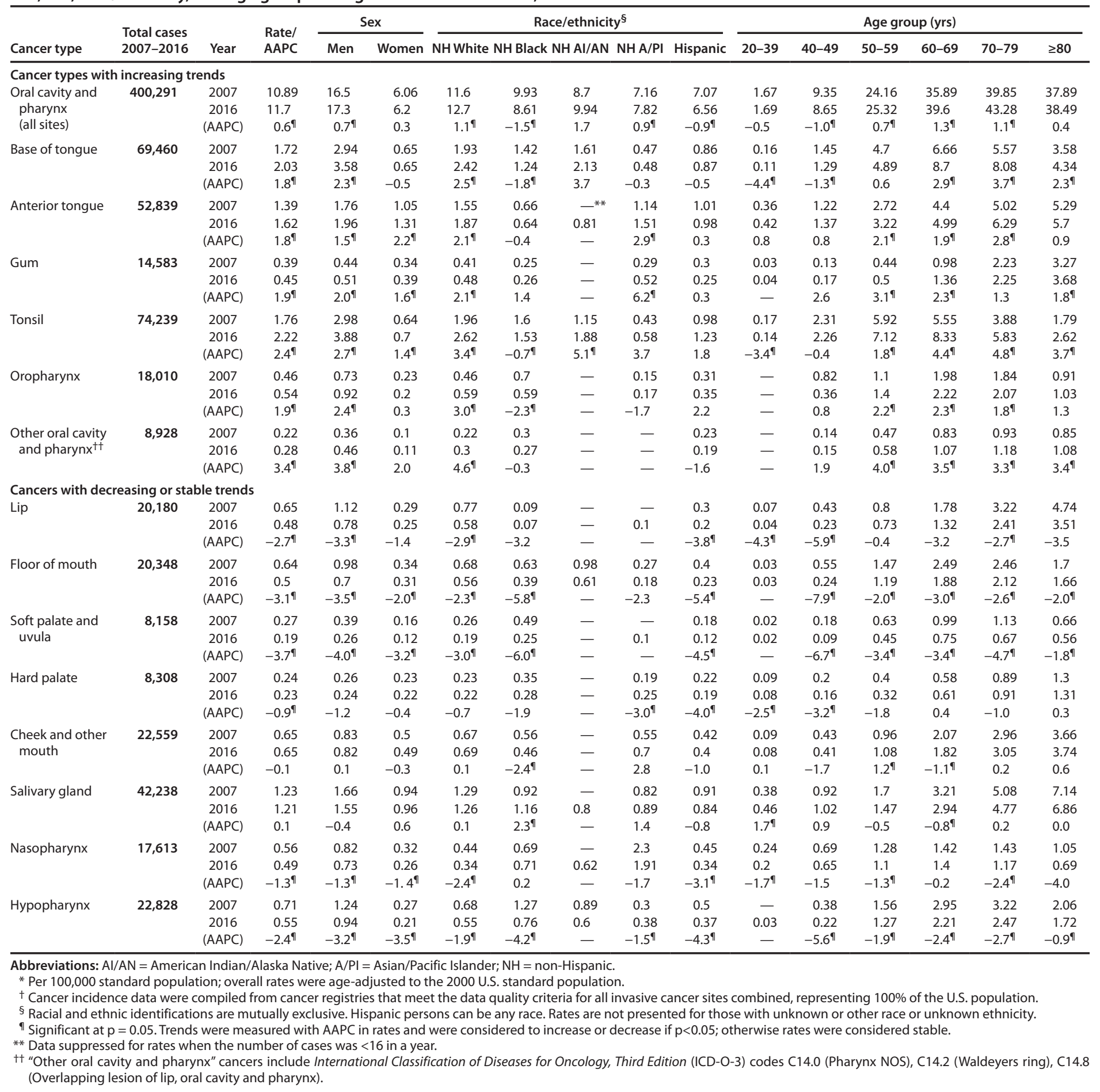

Cancers of the oral cavity and pharynx can be caused by exposure to risk factors that are common in the United States, including tobacco use, alcohol use, and HPV infection. Cancer control initiatives that use proven population-based strategies to prevent tobacco use initiation, promote smoking cessation, reduce alcohol use, and increase HPV vaccination rates could help reduce cancer risk. 


\section{Acknowledgments}

State and regional cancer registry staff members.

Corresponding author: Taylor D. Ellington, tellington@cdc.gov, 404-498-2258.

${ }^{1}$ Division of Cancer Prevention and Control, National Center for Chronic Disease Prevention and Health Promotion, CDC.

All authors have completed and submitted the International Committee of Medical Journal Editors form for disclosure of potential conflicts of interest. No potential conflicts of interest were disclosed.

\section{References}

1. Hashibe M, Sturgis EM, Ferlay J, Winn DM. Oral cavity, oropharynx, lip, and salivary glands [Chapter 29]. In: Thun MJ, Linet MS, Cerhan JR, Haiman CA, Schottenfeld D, eds. Cancer epidemiology and prevention, 4th ed. New York, NY: Oxford University Press; 2017.

2. Simard EP, Ward EM, Siegel R, Jemal A. Cancers with increasing incidence trends in the United States: 1999 through 2008. CA Cancer J Clin 2012;62:118-28. https://doi.org/10.3322/caac.20141

3. Chaturvedi AK, Engels EA, Anderson WF, Gillison ML. Incidence trends for human papillomavirus-related and -unrelated oral squamous cell carcinomas in the United States. J Clin Oncol 2008;26:612-9. https:// doi.org/10.1200/JCO.2007.14.1713
4. Van Dyne EA, Henley SJ, Saraiya M, Thomas CC, Markowitz LE, Benard VB. Trends in human papillomavirus-associated cancersUnited States, 1999-2015. MMWR Morb Mortal Wkly Rep 2018;67:918-24. https://doi.org/10.15585/mmwr.mm6733a2

5. Gillison ML, Chaturvedi AK, Anderson WF, Fakhry C. Epidemiology of human papillomavirus-positive head and neck squamous cell carcinoma. J Clin Oncol 2015;33:3235-42. https://doi.org/10.1200/ JCO.2015.61.6995

6. Saraiya M, Unger ER, Thompson TD, et al.; HPV Typing of Cancers Workgroup. US assessment of HPV types in cancers: implications for current and 9-valent HPV vaccines. J Natl Cancer Inst 2015;107:djv086. https://doi.org/10.1093/jnci/djv086

7. Sturgis EM, Cinciripini PM. Trends in head and neck cancer incidence in relation to smoking prevalence: an emerging epidemic of human papillomavirus-associated cancers? Cancer 2007;110:1429-35. https:// doi.org/10.1002/cncr.22963

8. Alattas M, Ross CS, Henehan ER, Naimi TS. Alcohol policies and alcohol-attributable cancer mortality in U.S. states. Chem Biol Interact 2020;315:108885. https://doi.org/10.1016/j.cbi.2019.108885

9. D’Souza G, McNeel TS, Fakhry C. Understanding personal risk of oropharyngeal cancer: risk-groups for oncogenic oral HPV infection and oropharyngeal cancer. Ann Oncol 2017;28:3065-9. https://doi. org/10.1093/annonc/mdx 535

10. Markowitz LE, Dunne EF, Saraiya M, et al. Human papillomavirus vaccination: recommendations of the Advisory Committee on Immunization Practices (ACIP). MMWR Recomm Rep 2014;63(No. RR-05). 